\title{
IMPLICATIONS OF AN AGING POPULATION ON PENSION SYSTEMS AND FINANCIAL MARKETS
}

\author{
by Tristan Nguyen ${ }^{1}$ - Ralf Stützle ${ }^{2}$
}

\begin{abstract}
In this paper, we introduce a macroeconomic model of overlapping generations to analyze the impacts of the demographic changes as well as the interactions between pension system, bond and stock markets. Furthermore, we examine how the pension system influences the distribution of wealth, consumption and saving within generations.

In the context of this model, we show a drastic decline of capital market returns due to an aging population. Moreover, we examine the impacts demographic changes can have on individuals'welfare for an existing pay-as-you-go pension scheme. Raising the pensionable age combined with a decrease of the contributions seems to be the best policy. On the other hand, increases in contributions as a result of demographic changes show the highest welfare losses. Taken into account the recent pension reforms in Germany, raising the retirement age or a faster transition from a pay-as-you-go pension system to a capital funded one would make sense. But it is questionable whether such a policy will be enforceable with an aging electorate.
\end{abstract}

Keywords: Pension Scheme, Demographic Change, Interest Rate, Overlapping Generations.

\section{INTRODUCTION}

How can pension schemes be sustainably financed? This is an important issue particularly with regard to the demographic changes in many industrialized countries but also in other emerging economies such as China and India. While the immediate concern is the financial market and currency crisis, the much more important challenge for capital markets over the medium and long-term is dealing with the implications of an aging population on pension systems and the role that financial markets can play in providing adequate private pensions.

Demographic changes are the result of steadily increasing life expectancy due to medical improvements and falling fertility rates $^{3}$. The hump-shaped profile of fertility rates has created the "babyboom" generation; that is, a generation or cohorts which are larger than the preceding and subsequent cohorts. Therefore, the effects of the baby-boom generation

\footnotetext{
${ }^{1}$ Prof. Dr. Tristan Nguyen is Chairholder at the Department of Economics, WHL Graduate School of Business and Economics in Lahr/Germany. He holds a PhD degree in Economics and a Habilitation (post-doc qualification) in Economics and Insurance Management from the University of Hagen after obtaining Master degrees in Economics, Business Administration, Laws and Mathematics. His fields of research include Financial Regulation, Public Finance, and Insurance Accounting. E-mail: tristan. nguyen@whl-lahr.de.

${ }^{2}$ Dr. Ralf Stützle is Research Fellow at the Department of Economics, WHL Graduate School of Business and Economics in Lahr/Germany. He holds a PhD degree in Physics and a Master of Business Administration (MBA). His fields of research include Public Finance and Social Security.

${ }^{3}$ National fertility levels are considered ,, too low" by majority of governments in developed countries, e.g. Kohler, H. P./Billari, F. C./Ortega, J. .A. (2006). Preston, S. H./Hartnett, C. S. (2011) analyze the future of american fertility.
} 
are only temporary as this generation born during the high fertility years pass away. On the other hand, the impacts of increasing life expectancy are of a more permanent nature. The implication of an aging population is an increasing ratio of people in retirement age compared to the working age population. The retirement of the baby boom generation will increase this share as those cohorts retiring will be followed by smaller cohorts. Analogously, improvements in life expectancy directly cause an increase of people in retirement at any given time. Due to the increased ratio of people in retirement relative to people of working age there are serious financial problems for pay-as-you-go financed pensions (mostly public pensions) as well as to funded pensions (generally private pensions) $)^{4}$.

Public pension schemes would see the number of young working people contributing dwindle relative to older retirees withdrawing benefits. This would cause increasing public expenditures on pensions. Additionally, many public pension systems are designed in the manner which creates incentives for early retirement and worsens the impacts of demographic changes on public pension expenditures $^{5}$. The aging population has, however, also negative effects on a capital funded pension system since the capital market return will drop due to the demographic change. This result can be explained by two effects:

- The capital intensity increases since the capital funded pension schemes initiate a higher capital accumulation in the whole economy. At the same time, the number of people in the workforce diminishes due to demographic changes. This leads to a price increase for the factor workforce and to a price decrease for the factor capital. The capital market return will consequently fall.

- A second argument is a predicted collapse of prices on the capital markets. Due to the many retired sellers and the low number of young buyers, the prices of the assets (shares, bonds, real estate etc.) must fall.

In this article, we introduce firstly a macroeconomic model of overlapping generations in which we can analyze the effects of the demographic changes on pension schemes as well as the interactions between pension systems on the one hand and capital markets on the other ${ }^{6}$. The model consists of three building blocks:

- A population model which describes the presumptions with respect to population development,

- Modeling of enterprises in view of the dependence between the existing pension system and the real economic variables such as wage and capital stock and

- Description of risks on financial markets as well as the interactions between pension systems and stock prices or interest rates.

Furthermore, we will examine the effects of pension systems on welfare distribution and consumption as well as the rate of saving within generations.

\section{THE MODEL}

\subsection{Population model}

To facilitate the modeling, the model uses discrete time steps $t \in N$. The

\footnotetext{
${ }^{4}$ Börsch-Supan, A./Ludwig, A (2011) analyze the effects of the aging process in France, Gemany and italy with pay-as-you-gofinanced social security systems.

${ }^{5}$ E.g. Duval, R. (2003).

${ }^{6}$ E.g. Gräf, B./Schattenberg, M. (2006); Börsch-Supan, A./Ludwig, A./Winter, J. (2006); Krueger, D./Ludwig, A (2007).
} 
population consists of $J+1$ generations. All consumers live for exactly $J+1$ time steps (overlapping generations model) and exhibit a homogeneous savings and consumption behavior within one generation. Such a model is particularly suited to describe the financial interactions between the generations. Each generation is identified in each period by an index $j=0 \ldots J$ that describes the remaining life expectancy. Consequently, $j=J$ is the youngest generation to be born at the beginning of the considered period, $j=0$ represents the oldest generation that dies at the end of the period. The entire population is thus represented by a vector $N_{t}=\left(N_{t}^{(j)}\right)_{j=0}^{J}$, where $N_{t}^{(j)}$ is the number of consumers in generation $j$ at the time $t$. The time evolution of the population is described by the birth rate $\mathrm{N}$ with:

$$
\begin{gathered}
N_{t}^{(j)}=N_{t-1}^{(j+1)} \quad j=0,1, \ldots, J-1 \\
N_{t}^{(J)}=\mathrm{N}\left(N_{t-1}\right)
\end{gathered}
$$

Equation (1) describes the aging of $\mathrm{N}\left(N_{t-1}\right)$, depending on the population the overlapping generations, equation structure in the period before. In the case (2) describes the birth rate as a function of a constant population we find:

$$
\mathrm{N}\left(N_{t-1}\right)=N_{t-1}^{(J)} \quad \Rightarrow \quad N_{t}^{(J)}=N_{t-1}^{(J)}=N_{t}^{(j)} \quad \forall t, j=0, \ldots J .
$$

For the numerical simulations in later sections of this work, the demographic change of the population is described by the

$$
\mathrm{N}\left(N_{t-1}\right)=\sum_{j=0}^{J} N_{t-1}^{(j)} n^{(j)}\left(1+\exp \left(-n_{2} \sum_{i=0}^{J} N_{t-1}^{(i)}\right)\right)
$$

Using $n_{2}=0$ we have constant growth rates and thus an exponential population change. For $n_{2}>0$ the birth rates decrease as a function of the total population $\sum_{i=0}^{J} N_{t-1}^{(i)}$. With the birth rates added up over all generations $n:=\sum_{j=0}^{J} n^{(j)}$ the asymptotic stationary value is obtained

$$
\overline{\mathrm{N}}:=\frac{1}{(J+1) n_{2}} \ln \frac{n}{1-n},
$$

so that the population tends to the constant distribution $N^{*}=(\overline{\mathrm{N}})_{j=0}^{J}$.

Furthermore, the model of working $\left(j=j_{L}, . ., J\right)$ provides $\bar{L}^{(j)}$ units of overlapping generations contains a labor to the workforce market. The total labor retirement threshold $j_{L}$ for the consumers. supply of the economy $L_{t}^{s}$ is given by: It is assumed that each member of the

$$
L_{t}^{s}:=\sum_{j=j_{L}}^{J} \bar{L}^{(j)} N_{t}^{(j)}
$$

For simplicity it is assumed that you-go system, so that each worker with taxes do not exist in the model. A share $\tau_{t}$ the gross wage per unit of work $\omega_{t}$ gets the of gross wages has to be paid in a pay-as- net wage: 


$$
e_{t}^{(j)}=\left(1-\tau_{t}\right) \omega_{t} \bar{L}^{(j)}, \quad j \geq j_{L}
$$

The pension income is composed of total income from work activities, divided the product of the contribution rate and the by the number of pensioners:

$$
e_{t}^{(j)}=\tau_{t} \frac{\omega_{t} L_{t}^{s}}{\sum_{j=0}^{j_{L-1}} N_{t}^{(j)}} \quad j<j_{L}
$$

All individuals can consume their current wealth in a period or transfer it to the next period by two investment opportunities. Using these two alternatives, there is also the possibility to provide for the retirement phase. On the one hand, there is a corporate bond with a maturity of one period available. This may be traded at time $t$ at unit price and attains in the next period $t+1$ one from the company's success dependent return $R_{t}$. As $R_{t}$ is determined at time $t$, the bond is a risk-free opportunity to transfer wealth to the next period. As an alternative, an investment in shares is possible. The shares are traded on the rates $p_{t}$ and deliver in each period a stochastic dividend $d_{t}$. In the model short-selling of bonds is possible ("credit"), whereas for shares this is not possible. The portfolio of a consumer $j \in$ $1, \ldots, J$ is described by $z_{t}^{(j)}:=\left(y_{t}^{(j)}, x_{t}^{(j)}\right)$. Here $y_{t}^{(j)}$ is the number of bonds and $x_{t}^{(j)}$ is the number of owned shares.

The wealth $w_{t}^{(j)}$ of a consumer is given as the sum of wage or pension income and the income from capital investment decisions $z_{t-1}^{(j)}$ of the previous period.

$$
w_{t}^{(j)}:=\left\{\begin{array}{cc}
e_{t}^{(j)}, & j=J \\
e_{t}^{(j)}+R_{t-1} y_{t-1}^{(j+1)}+x_{t-1}^{(j+1)}\left(p_{t}+d_{t}\right), & j=0,1, \ldots, J-1 .
\end{array}\right.
$$

It is assumed that all individuals are selfish and do not pass on an inheritance. This implies that consumers in their last period of life sell all shares and do not buy bonds.

\subsection{Consumer Behavior}

This section describes the decisionmaking process, which part of their wealth the individuals use for consumption and how they invest the rest in bonds or shares. The goal of the individual here is to maximize their wealth within a planning horizon.
The decisions are influenced by expectations of the consumers regarding their future wage or pension income $\hat{e}=\left(\hat{e}_{1}, \ldots, \hat{e}_{N}\right)$ and the expected bond yield $\hat{R}=\left(\hat{R}_{1}, \ldots, \hat{R}_{N-1}\right)$ within the planning horizon of $N$ periods. In addition, the decisions are influenced by the uncertainty regarding the impact of unforeseen developments of stock prices and dividends. For the consumer different strategies for consumption $c$, bond investment $y$ and share investment $x$ are available. Within the planning horizon a strategy has to fulfill the following conditions in each period:

$$
\begin{gathered}
c_{0}+y_{0}+x_{0} p_{0}=w_{0} \\
c_{n}+y_{n}+x_{n} p_{n}=\hat{e}_{n}+\hat{R}_{n-1} y_{n-1}+x_{n-1}\left(p_{n}+d_{n}\right) n=1, \ldots, N
\end{gathered}
$$


This must be met for all possible (random) stock prices $p_{n}$ and dividend payments $d_{n}$. The existence of such a strategy under certain constraints, which

$$
U^{(j)}=\ln \left(c_{0}\right)+\sum_{n=1}^{j} \beta^{n} \ln \left(c_{n}\right) .
$$

The discount rate $\beta$ represents the general fact that individuals prefer consumption in the presence compared to consumption in the future.

It has been found that it is not necessary to consider the entire planning horizon in the model ${ }^{9}$. The decision problem can be traced back to a singlestage problem, so that demand functions are specified which describe the optimized consumer demand for one period. The

$$
v_{q}=\frac{1}{\xi} \exp \left(-\frac{(q-\mu)^{2}}{2 \Sigma}\right)
$$

Thus we get the following, share demand $\varphi_{x, t}^{(j)}$ and bond demand $\varphi_{y, t}^{(j)}$ expressions for the benefit optimized for each generation ${ }^{10}$. values for tendency for consumption $\varphi_{c, t}^{(j)}$

$$
\begin{aligned}
& \varphi_{c}=\bar{c}\left(w+\hat{\varepsilon}_{0} / R\right) \\
& \varphi_{x}=(1-\bar{c})\left(w+\hat{\varepsilon}_{0} / R\right) \theta\left(R p, v_{q}\right) / p \\
& \varphi_{y}=(1-\bar{c})\left(w+\hat{\varepsilon}_{0} / R\right)\left(1-\theta\left(R p, v_{q}\right)\right)-\hat{\varepsilon}_{0} / R
\end{aligned}
$$

where $\hat{\varepsilon}_{0}$ is the discounted expected future income:

$$
\begin{gathered}
\hat{\varepsilon}_{0}:=\hat{e}_{1}+\frac{\hat{e}_{2}}{\hat{R}_{1}}+\ldots+\frac{\hat{e}_{j}}{\hat{R}_{1} \cdots \hat{R}_{j-1}} \\
\bar{c}=\frac{1}{1+\beta+\ldots+\beta^{j}} \\
\theta\left(R p, v_{q}\right)=\arg \max _{\vartheta}\left(\int \ln (R p+\vartheta(q-\pi)) v_{q} d q\right)
\end{gathered}
$$

The functions $\varphi$ provide the consumption, investment in shares or optimum with respect to tendency of bonds, as a function of the prices $R$ and

${ }^{8}$ Hillebrand, M. (2008), p. $15 \mathrm{ff}$.

${ }^{9}$ Hillebrand, M. (2008), p. $20 \mathrm{ff}$.

${ }^{10}$ The indices $j$ and t are for clarity not explicitly specified in the following. 
$p$ and wealth $w$, as well as expectations $\hat{\varepsilon}_{0}$ and $\mu$. The optimal consumption is a fraction $\bar{c}$ of the sum of current wealth $w$ and the discounted expected income $\hat{\varepsilon}_{0}$ $/ R$. This amount is referred to as lifetime earnings. The percentage of consumption only depends on the discount factor $\beta$ and is independent from expectations of future financial market prices ${ }^{11}$.

For the consumer only the wealth $w$ is directly available. The quantity $\hat{\varepsilon}_{0} / R$ has to be compensated by short-selling of bonds. For this reason the term $\hat{\varepsilon}_{0} / R$ appears in the function for the bond demand. The optimum volume of shares is determined by the variable $\theta$, which is only influenced by present $(R, p)$ and via $v_{q}$ by expected $(\mu, \Sigma)$ financial market prices.

In order to get a quantitative evaluation of the model, a concrete behavior of how the consumers form their expectations regarding the financial market variables has to be assumed. For consumer expectations the following assumptions are made: Each consumer assumes to achieve in a future period the income that a consumer of the appropriate age, in the current period receives:

$$
\hat{e}_{t, t+n}^{(j)}=e_{t}^{(j-n)}, n=1, \ldots j, j=1, \ldots, J
$$

Regarding the bond yield consumers expect stability of the current value.

$$
\hat{R}_{t, t+n}=R_{t-1}, \quad n=1, \ldots, J-1
$$

For the expectation of future stock prices including dividends $\mu_{t}$, the consumer corrects in each period, its previous

$$
\mu_{t}=\mu_{t-2}+\rho\left(q_{t-1}-\mu_{t-2}\right) \quad 0 \leq \rho \leq 1
$$

2.3. Model of Company Decisions its capital stock $K_{t}$ and labor $L_{t}$ to produce.

In this section, the production and investment behavior of the business side is modeled. For simplicity, only one company is considered. In each period $t$ the firm uses

$$
F\left(L_{t}, K_{t}, \eta_{t}\right)=\kappa L_{t}^{\alpha} K_{t}^{1-\alpha}+\eta_{t}, \quad \kappa>0, \alpha \in[0,1]
$$

The time evolution of the capital rate $\delta$ and the investment $I_{t}$ : stock is determined by the depreciation

$$
K_{t+1}=I_{t}+(1-\delta) K_{t} .
$$

The entrepreneurial investment decision $I_{t}$ is financed only by issuing a number of bonds $B_{t}$ at unit price. In the following it is assumed that there is no proportionality between capital stock increase $I_{t}$ and the collected amount of

money $B_{t}{ }^{12}$ Instead, it is assumed that the larger the desired ratio of investment $I_{t}$ to existing capital stock $K_{t}$ the more money must be taken in order to achieve the desired capital stock increase. The link is called "adjustment cost function".

\footnotetext{
${ }^{11}$ This is a special property of the logarithmic utility function in equation (12).

${ }^{12}$ E.g. Abel, A. B. (2003) or Altig, D. et al. (2001).
} 


$$
\begin{array}{cc}
B_{t}=0 & I_{t}=0 \\
B_{t}=K_{t} \gamma_{0} \exp \left(\gamma_{1} I_{t} / K_{t}\right) & I_{t}>0, \gamma_{0}>0, \gamma_{1}>1 / \delta
\end{array}
$$

This function is discontinuous at in period $t+1$ the $\operatorname{sum} R_{t} B_{t}$ to the investor. $I_{t}=0$. This reflects the fact that in case of In addition to paying off the bonds, the no investment no money is needed, while company has to pay the gross wages. It at a minimal investment already fixed is assumed that the remaining money costs $K_{t} \gamma_{0}$ accrue.

The bonds that have been issued in period $t$ in order to finance the investment decision generate the obligation to pay of shares):

$$
d_{t}=\frac{F\left(L_{t}, K_{t}, \eta_{t}\right)-\omega_{t} L_{t}-R_{t-1} B_{t-1}}{\bar{x}}
$$

How does the company make of the subsequent period determines the decisions? What amount of labor is investment decision. In detail: At a decision needed? How much should be invested? point, the company has a capital stock $K_{t}$, As part of the model it is believed that these knows the environmental impact $\eta_{t}$ and the decisions are made under the constraint of bond repayment $R_{t-1} B_{t-1}$ from the investment maximum dividend payments. On the one decision in the previous period. The gross hand, the demand for a maximum dividend wage $\omega_{t}$ is treated here as a parameter. By payout in the current period, determines the partial derivation of (27) with respect to $L_{t}$ labor demand in this period, on the other an extremum of $d_{t}$ for the labor demand at a hand, the desire to maximize the dividend given wage level $\omega_{t}$ can be found.

$$
L_{t}=\left(\frac{\alpha \kappa}{\omega_{t}}\right)^{\frac{1}{1-\alpha}} K_{t}
$$

For the investment decision it is assumed that the dividend in the next period.

$$
d_{t+1}=\frac{F\left(L_{t+1}, K_{t+1}, \eta_{t+1}\right)-\hat{\omega}_{t+1} L_{t+1}-R_{t} B_{t}}{\bar{x}}
$$

should be maximized. Here $\hat{\omega}_{t+1}$ is the derivative $\partial d / \partial I$, zero-setting and using expected wage level of the next period. equation (28) follows for the optimal With $K_{t+1}$ from equation (24) and partial investment level:

$$
I=\frac{1}{\gamma_{1}} \ln \left(\frac{(1-\alpha) \kappa}{\gamma_{0} \gamma_{1} R}\left(\frac{\alpha \kappa}{\hat{\omega}_{t+1}}\right)^{\frac{\alpha}{1-\alpha}}\right) K_{t}
$$

This results in the bond offer

$$
B=\frac{(1-\alpha) \kappa}{\gamma_{1} R}\left(\frac{\alpha \kappa}{\hat{\omega}_{t+1}}\right)^{\frac{\alpha}{1-\alpha}} K_{t}
$$


For the specific determination of can be used. In this work, the assumption wage expectations $\hat{\omega}_{t+1}$ different models of constant wages is used:

$$
\hat{\omega}_{t+1}=\omega_{t}
$$

2.4. Time Evolution of the Model and Formation of Equilibrium Price

Using the models derived in the previous sections for behavior of consumers and companies, we can now determine the market equilibrium. Within the sequential structure of the model this is done at a time $t$ by means of five steps. From the previous period $t-1$ the population $N_{t-1}$, capital stock $K_{t-1}$, company investment $I_{t-1}$, share and bond investment of consumers $z_{t-1}=\left(x_{t-1}^{(j)}, y_{t-1}^{(j)}\right)_{j=1}^{J}$ bond volume $B_{t-1}$ and bond yield $R_{t-1}$ are given.

Step 1: At the beginning of the period the development of the population takes place. The population $N_{t}$ develops from $N_{t-1}$ according to the model from section 3.1. It follows the labor supply during the current period according to equation (6). The capital stock of the current period is given by the capital stock and investments of the previous period from equation (24).

Step 2: Using the labor demand function of the company according to equation (28), the labor supply equation (6) and the assumption of a cleared labor market ( $L_{t}^{s}=L_{t}$, full employment) it is possible to derive the equilibrium gross wage $\omega_{t}$ of the period $t$ :

$$
\omega_{t}=\kappa \alpha\left(\frac{K_{t}}{L_{t}^{s}}\right)^{1-\alpha}
$$

Depending on the preset contribution rate $\tau$ of the pay-as-you-go system, the income of the consumers without investment income follows according to equations (7) and (8). According to the effect of random production shock $\eta_{t}$ the dividend payment $d_{t}$ for the current period is determined using equation (27).

Step 3: Based on these results each consumer forms the expectations for the next periods. For the income equation (20) is valid, for the expected bond yield (21) is used and the expectations for the stock prices follow equation (22). The companies make predictions on the wages of the next period according to equation (32). Based on these expectations the consumers form their demand behavior according to equations (14) - (16). The company determines the bond volume according to equation (31).

Step 4: From the previous steps result share and bond demand and bond offering. The prices are obtained from market clearing conditions. These are for the stock and bond market:

$$
\begin{aligned}
& \sum_{j=1}^{J} N_{t}^{(j)} \varphi_{x}^{(j)}=\bar{x} \\
& \sum_{j=1}^{J} N_{t}^{(j)} \varphi_{y}^{(j)}=B_{t}
\end{aligned}
$$


Therefore we get for the actual period $t$ the bond yield $R_{t}$ and the stock price $P_{t}$.

$$
\begin{aligned}
& R_{t}:=\frac{B+\sum_{j=1}^{J} N_{t}^{(j)} \bar{c}^{(j)} \hat{\varepsilon}_{0, t}^{(j)}+\pi_{t} \sum_{j=0}^{J-1} N_{t}^{(j)} \bar{c}^{(j)} x_{t-1}^{(j+1)}}{\sum_{j=1}^{J} N_{t}^{(j)}\left(1-\bar{c}^{(j)}\right) e_{t}^{(j)}+\sum_{j=1}^{J-1} N_{t}^{(j)}\left(1-\bar{c}^{(j)}\right)\left[R_{t-1} x_{t-1}^{(j+1)}+d_{t} x_{t-1}^{(j+1)}\right]} \\
& p_{t}:=\frac{\pi_{t}}{R_{t}}
\end{aligned}
$$

With

$$
\pi_{t}=\mu_{t}-v_{t}\left(\mu_{t}, \Sigma_{t}, N_{t}, K_{t}, \hat{e}_{t}, \hat{R}_{t}, \hat{\omega}_{t}\right) \Sigma \bar{x}
$$

Here $\pi_{t}$ is an adoption of the from two nested implicit equations, which expectation $\mu_{t}$ to reality. The correction are listed here without derivation ${ }^{13}$. depends on the function $v_{t}$ which results

$$
1-\frac{\lambda^{*}\left(\mu_{t}-v_{t} \Sigma \bar{x}, \mu_{t}, \Sigma\right)}{\bar{x} \sqrt{\Sigma}}\left(\mu_{t} \bar{x}-v_{t} \Sigma \bar{x}^{2}+\sum_{j=1}^{J} N_{t}^{(j)} \hat{e}_{0, t}^{(j)}+B_{t}\right)=0
$$

The auxiliary value $\lambda^{*}$ is derived chosen such that negative $q$-values are from the solution of the following equation, prevented where the finite limit of integration $\bar{\varepsilon}$ is

$$
\int_{-\bar{\varepsilon}}^{\bar{\varepsilon}} \frac{\frac{\mu_{t}-\pi_{t}}{\sqrt{\Sigma}}+\varepsilon}{1+\frac{\mu_{t}-\pi_{t}}{\sqrt{\Sigma}} \lambda+\lambda \varepsilon} v_{\varepsilon} d \varepsilon=0
$$

For the previously determined and bonds is satisfied and it is thus: prices, the consumer demand for stocks

$$
\begin{aligned}
& x_{t}^{(j)}=\varphi_{x}^{(j)}, \quad j=1, \ldots, J \\
& y_{t}^{(j)}=\varphi_{y}^{(j)}, \quad j=1, \ldots, J \\
& B_{t}=B
\end{aligned}
$$

Step 5: Finally, the individuals company uses the money obtained by make their consumption decision and the issuing bonds to fund the investments:

$$
\begin{gathered}
c_{t}^{j}=\varphi_{c}^{(j)}, \quad j=0,1, \ldots, J \\
I_{t}=I
\end{gathered}
$$

With this procedure, the development of the model is set within a period. For the next period in time the sequence begins again.

\subsection{Calibration of the Model}

In this section the parameters for the simulations are presented and motivated. The free parameters shall approximate 
reality. The values that are used have been derived from empirical studies.

For the simulations with the OLGmodel at first a constant population with $N_{t}^{(j)}=\bar{N}=1000$ consumers is assumed. Afterwards a dynamic population is studied. For life expectancy we use in both chapters $J=14$ and the retirement age is set to $j_{L}=6$. Consequently, always 15 generations live at the same time. Thereof nine go to work and six are retired. Assuming that an individual consumes during 60 years (a childhood phase without consumption does not exist in the model), then a time step in the model corresponds to four years of life. Any consumer who is not already in retirement, provides one unit $\bar{L}^{j}=1$ to the labor market. The discount rate $\beta$, that is relevant for the optimization of the consumers, is taken from an empirical study ${ }^{14}$. This results in a discount rate of 0.011 corresponding to an annual discount factor of $1 / 1.011$. With a time basis of four years $\beta=(1 / 1.011)^{4} \approx 0.96$ is obtained.

The constant parameters of the stock price expectancy are set to values of $\bar{\varepsilon}=0.92$ for the maximum share price variation and $\Sigma=0.97$ is the width of the Gaussian distribution. The parameter $\rho$, that describes the temporal adjustment of the expectation value $\mu_{t}$ is set to $\rho=0.5$. For the parameter $\alpha$ in the production function empirical studies found values between 0.6 and 0.7 . For the simulations a value of $\alpha=0,66$ is used. The parameter $\kappa$ in the production function serves essentially as a scaling factor and is set to the value $\kappa=2.5$. The average annual depreciation rate in Germany between 1960 and 1990 was approximately $0.0528^{15}$ Within the four year period of the simulation step $\delta=1-(1-0.0528)^{4} \approx 0.2$ is therefore used. For the adjustment cost function $\gamma_{0}=0.02$ and $\gamma_{1}=7.5$ is used, in order to fit empirical studies $^{16}$ in form of equation (26). As a size for the production shocks $\eta$ uniformly distributed random numbers between 0 and 2000 were used. As initial values we use for the capital stock $K_{0}=11500$, for stock prices including dividends $q_{0}=14,5$ and for bond yield $R_{0}=1,14$. Stock and bond volume are initially equally distributed across all generations.

\section{SIMULATION RESULTS}

In this section simulation results are presented which were determined using the previously described model. At first some basic properties of the model were demonstrated using a constant population. Then, the interactions between the pension system and an aging population are analyzed.

\subsection{Results for a Constant Population}

First of all, the possibilities of the model are shown for the case of a stationary population. The contribution rate is set to the value $\tau=0.1$. The implementation of the simulation code was done using MATLAB.

\footnotetext{
${ }^{14}$ E.g. Hurd, M. D. (1989), p. 801.

${ }^{15}$ E.g. Börsch-Supan, A. et al. (2003), p. 167.

${ }^{16}$ E.g. Abel, A. B. (2003) and Altig, D. et al. (2001).
} 
Figure 1. Time evolution of the simulation parameters for $\tau=0.1$ and a constant population
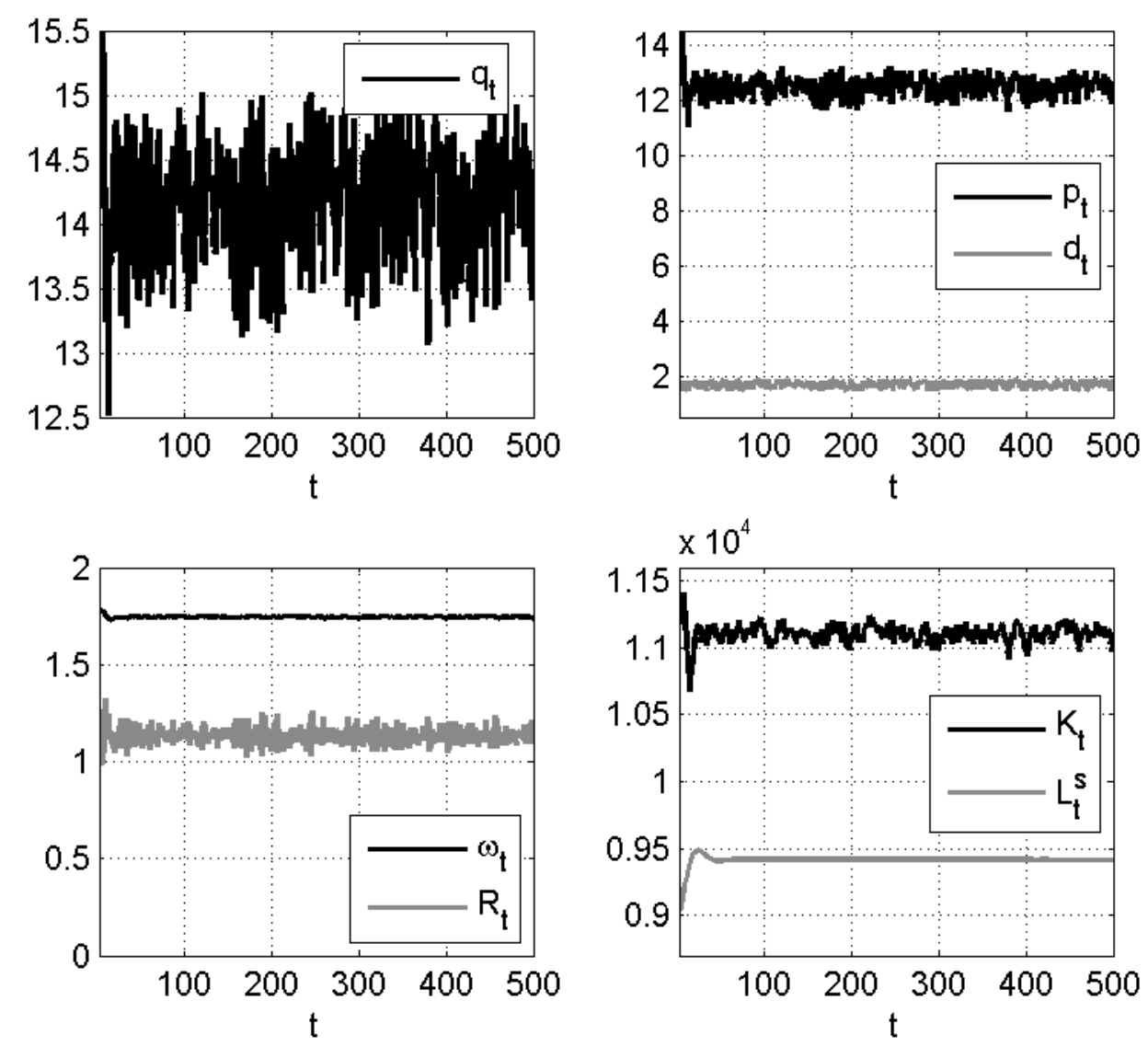

Figure 1 shows the time evolution of the model with the previously calibrated parameters and the presented population model. It reaches its equilibrium state already at $t=50$, resulting in a constant labor supply $L_{t}^{s}$. Therefore the figure shows for $t>50$ the dynamics of the other parameters for the case of a constant population. The figure also serves to verify the consistency of the simulation. For $t>50$ all parameters fluctuate around a fixed value. It turns out that the wages are very stable compared

to the financial market variables. The fluctuations in stock prices including dividends $q_{t}$ are essentially caused by the fluctuations of the stock prices themselves and to a small extent by the volatility of dividends. We also find, as expected, a positive correlation between stock prices and dividend payments. The bond yield $R_{t}$ fluctuates around a value of 1.135 , which corresponds to an annual interest rate of about $3 \%$. This is consistent with the empirical expectation. 
Figure 2. Dependence on the contribution rate $\tau$ for the average values and standard deviations.
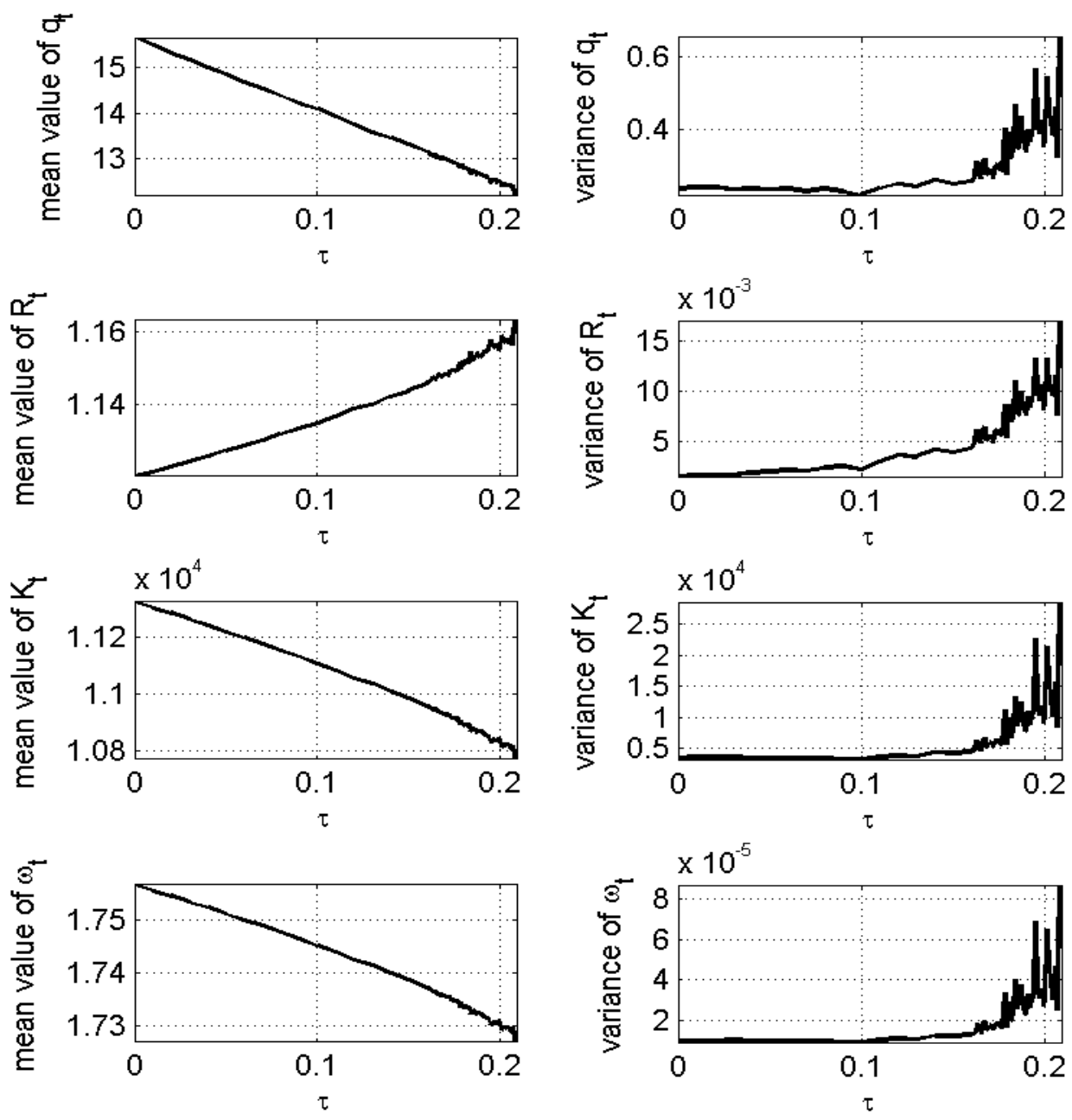

In order to investigate the influence of the pension system on the variables in the following the contribution rate $\tau$ is varied (Figure 2). It is immediately obvious that when decreasing the contribution rate the capital stock increases. The basic assumption, that a funded system is superior to a pay-as-you-go system is depicted in the model. In addition, it can be seen that the average for the stock price including dividends decreases with an increasing contribution rate, whereas the bond yield increases.

Furthermore the variability around the time average (characterized by the standard deviation) increases significantly with increasing contribution rates. It can

also be recognized that the model breaks down at a value of $\tau>0.21$. Here the model fails because consumers go bankrupt. A more detailed analysis of the strong fluctuations shows that they are caused by fluctuations of the stock prices and not by the dividends. The wage level is largely independent of the contribution rate. Here also hardly any impact of the large fluctuations of the financial market variables for large contribution rates can be found.

Figure 3 shows the steady state distribution across generations for the variables $y$ (bonds), $x$ (shares), $w$ (wealth) and $c$ (consumption). 
Figure 3. Volume of bonds, shares, wealth and consumption across generations
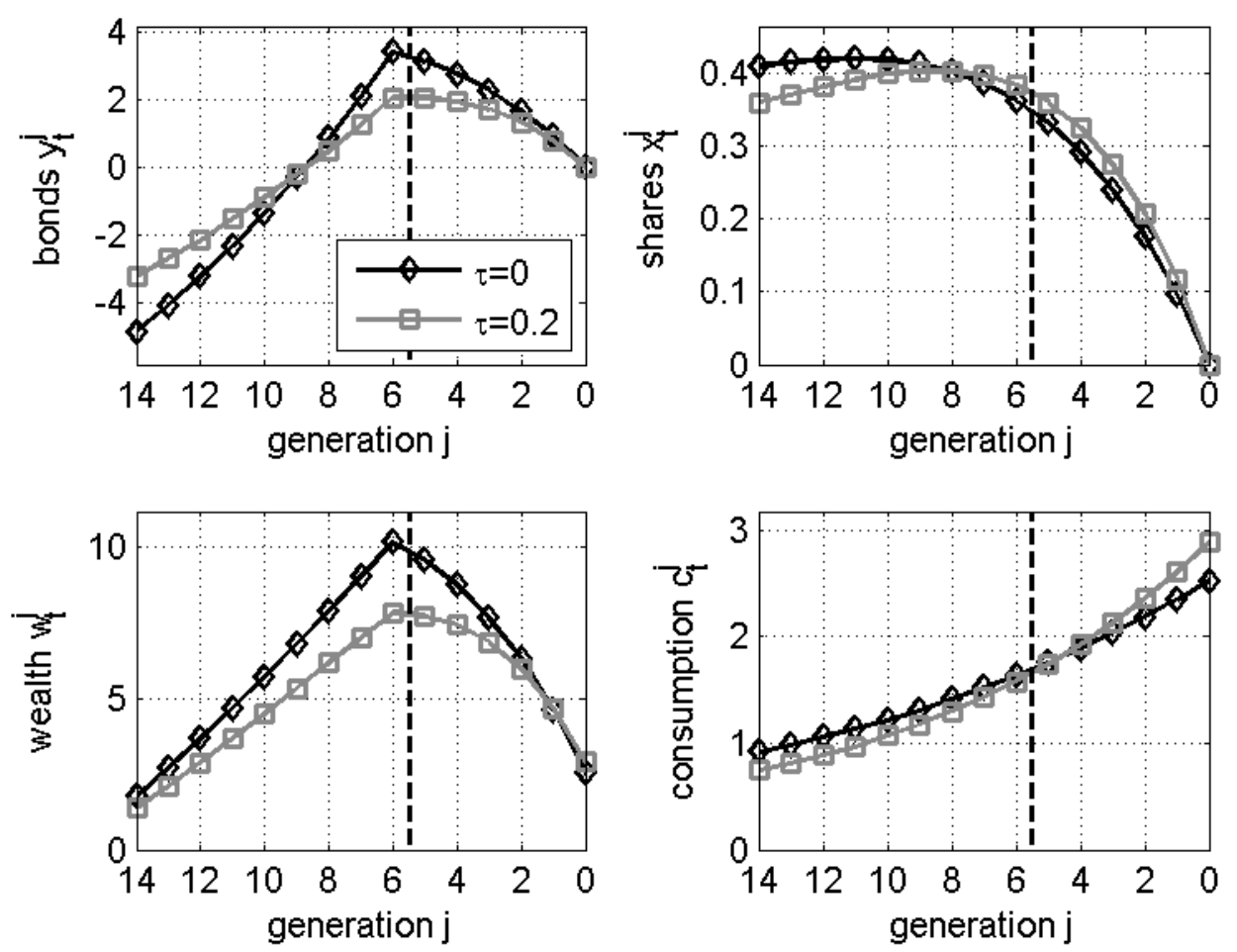

It is striking that young consumers secure credit by short selling of bonds. The borrowing is reduced with time, until for $j<9$ the bonds become an investment opportunity. The high-risk form of investment in the stock market is used more specifically in young years, the shares are sold with age. This appears more strongly in the absence of a pay-as-you-go system $(\tau=0)$. In this case the wealth is for all times larger than with a pay-as-you-go system. The consumers successfully compensate the missing pension income in retirement age by additional capital income. The

wealth reaches in both cases the maximum value just before the end of the working period. The consumption, however, rises in both cases monotonically with increasing age, where the increase for $\tau=0.2$ is steeper. This shows that without a pay-as-you-go system, consumption moves forward, and is even distributed more homogeneously over the many stages of life.

To assess which pension system is beneficial for the population, the lifetime welfare in the form of the following dimensionless variable is examined:

$$
U_{t}(\tau)=\sum_{j=0}^{J} \beta^{J-j} \ln c_{t-j}^{(j)}
$$

For each time $t>J$ the variable describes the welfare over the lifetime of a consumer belonging to generation $J$, who was born in period $t-J$ and will die at the end of period $t$. In figure 4 , this welfare function is shown. 
Figure 4. Welfare in case of a constant population for different contribution rates.

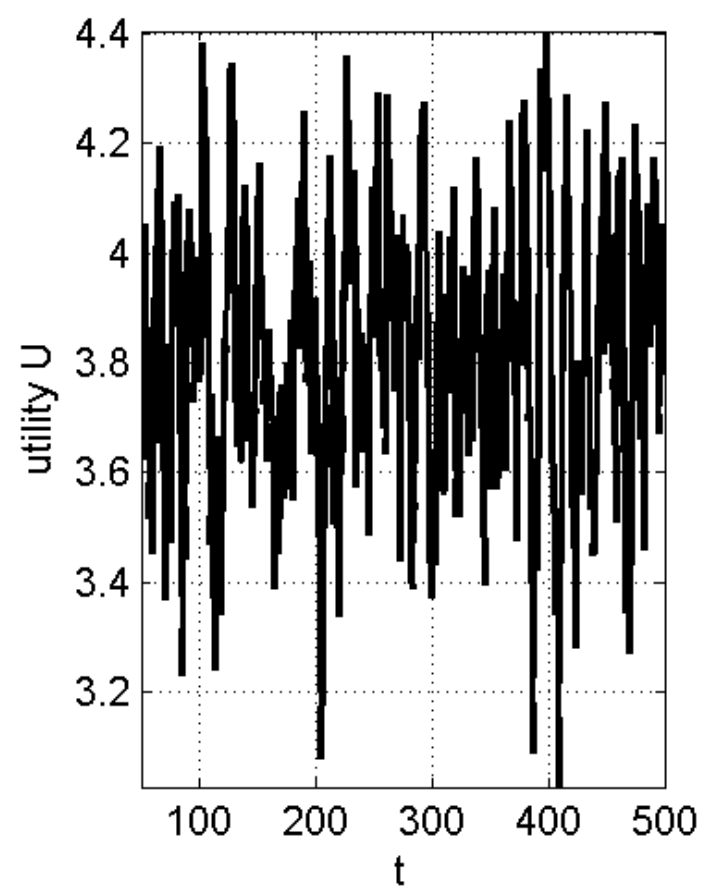

For a stationary population, a higher contribution rate leads to a reduction of the lifetime welfare. Consequently, for a constant population the introduction of a pay-as-you-go system is not advisable. In an existing system, the contribution rates should be reduced in order to achieve a long-term gain of welfare for all generations. In the long run an existing pay-as-you-go system should be abolished. The problem is that following a reduction of contribution rates, the retired generation at this time suffers from welfare losses. It is important therefore, to make the changeover as gently as possible.

\subsection{Results for an Aging Population}

In this section we examine how the model responds to changes in population structure. The German population will age dramatically in the coming years. For a pension system the relevant parameter is the ratio of the number of contributors to the number of recipients (economic dependency ratio). There is a difference if we look at the entire population. This is

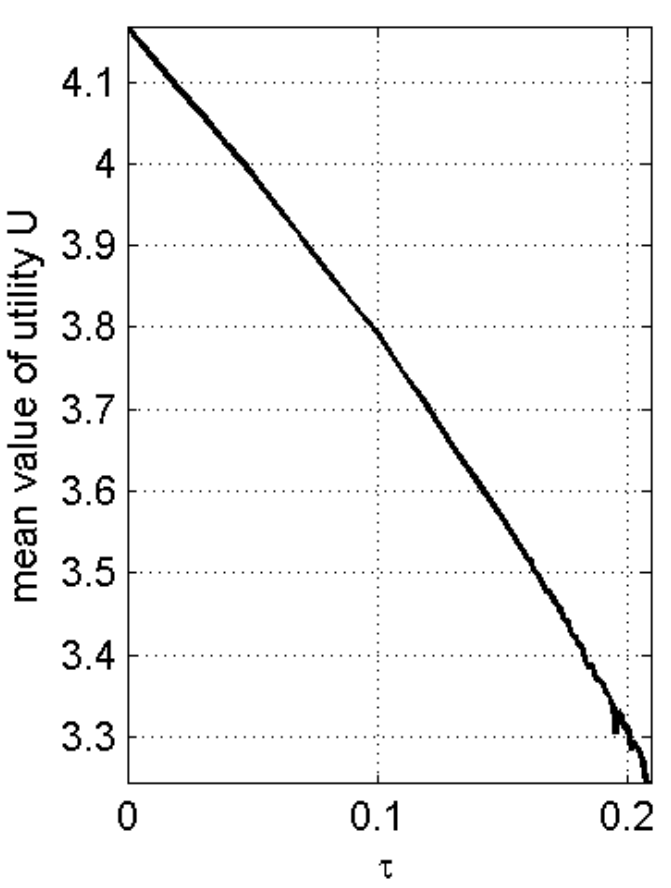

based on the fact that not all young people are actually contributors (unemployment, employment inclination). Börsch-Supan ${ }^{17}$ investigated the transfer of the elderly dependency ratio into predictions of the economic dependency ratio. It is essentially a scaled course of the elderly dependency ratio, with an increase of $66 \%$ in 2010 to one (scenario-dependent) rise up on a range of $>100 \%$ by 2030 .

In the model discussed here, all consumers are also contributors, thus both parameters coincide. To simulate the aging curve, the birth development shown in figure 8 was used. For $t<50$ the population is constant. This initial time phase is used to bring the model to its steady state. At $t=50$ the onset of a demographic change is modeled by reducing the generation dependent birth rates $n^{(j)}$ in each period by $1.4 \%$. For $t>70$ at each time step a reduced adjustment of the birth rates is applied in order to model the slower and almost linear increase of the elderly dependency ratio. 
Figure 5. Population dynamics in the model
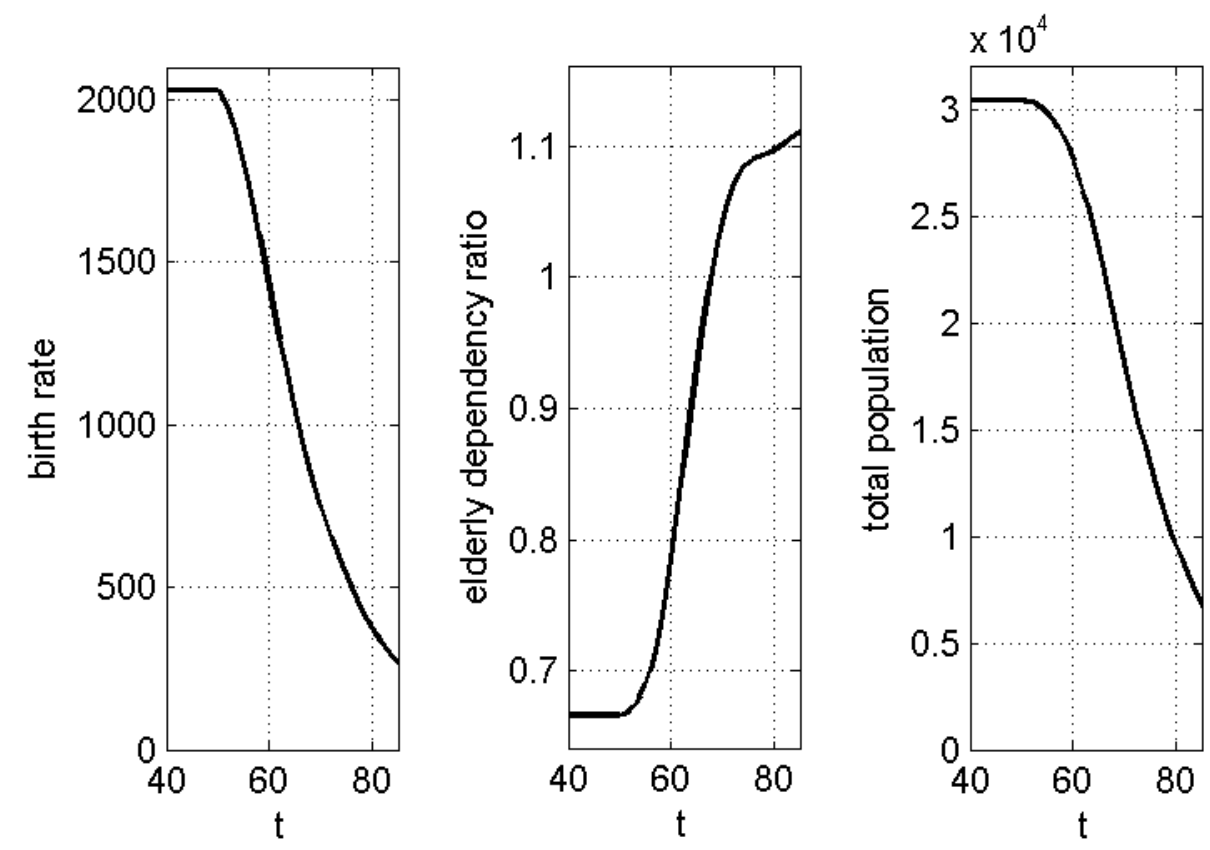

This results in the dependency ratio shown in the center graph of figure 5. This model is close to the forecast. The development of the total population shown in the right graph is not very realistic. This is because part of the aging is due to an increase in life expectancy, while in the model all individuals always reach the same age. The aging therefore had to be fully modeled by changing the birth rates. In addition, the aging of the population was slowed in order not to overstretch the model ( 1 time step $=4$ years $)$.

Figure 6 and 7 show the time evolution of the model parameters for an aging population with contribution rates $\tau=0$ and $\tau=0.2$. Most striking is the drastic decline in stock prices and capital stock. Both variables are dramatically reduced. The drop is largely independent of the contribution rate and in the magnitude comparable to the decrease in the total population. This decline in stock prices is know as the phenomenon of ,asset market meltdown" and has been predicted by several models ${ }^{18}$. Wages are rising slightly due to the scarcity of the labor supply. Also the bond yield increases slightly.

${ }^{18} \mathrm{Abel}$, A. B. (2001), p. $589 \mathrm{ff}$. 
Figure 6. Parameter dynamics for $\tau=0$ in presence of aging
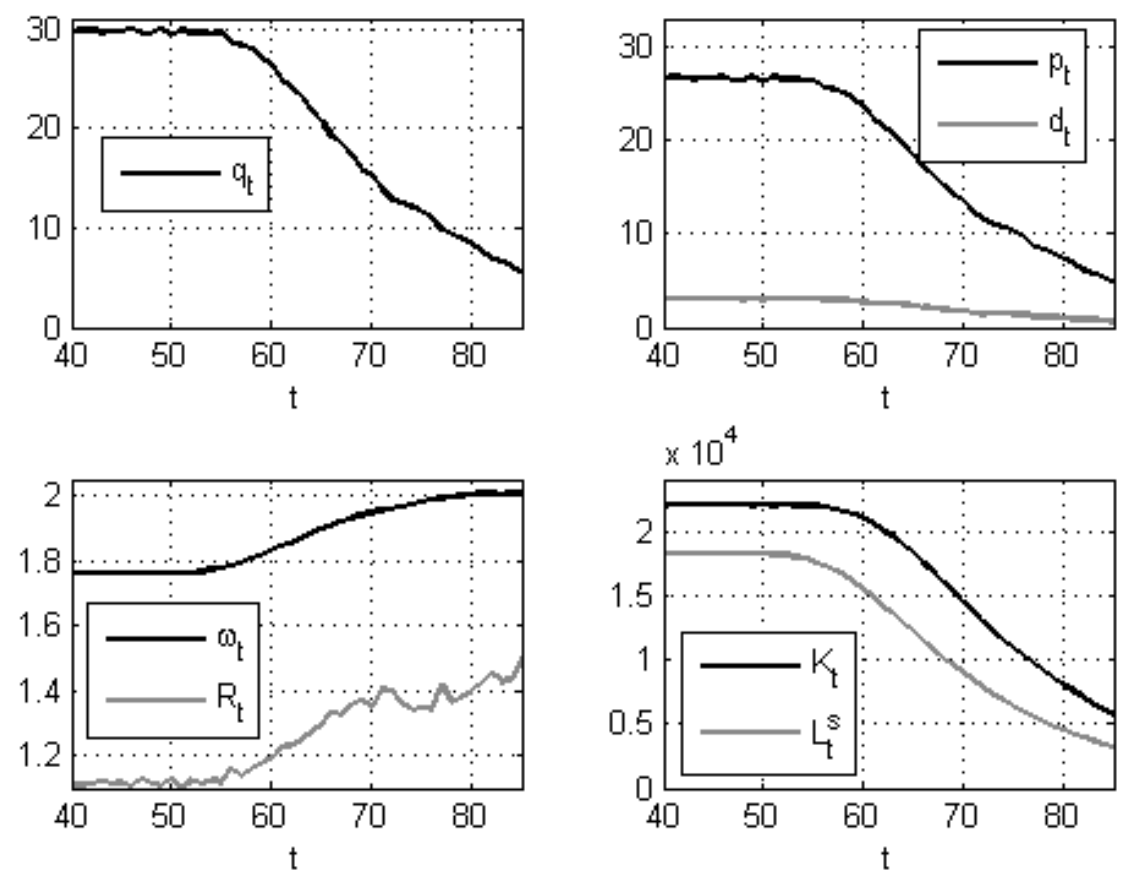

Figure 7. Parameter dynamics for $\tau=0,2$ in presence of aging
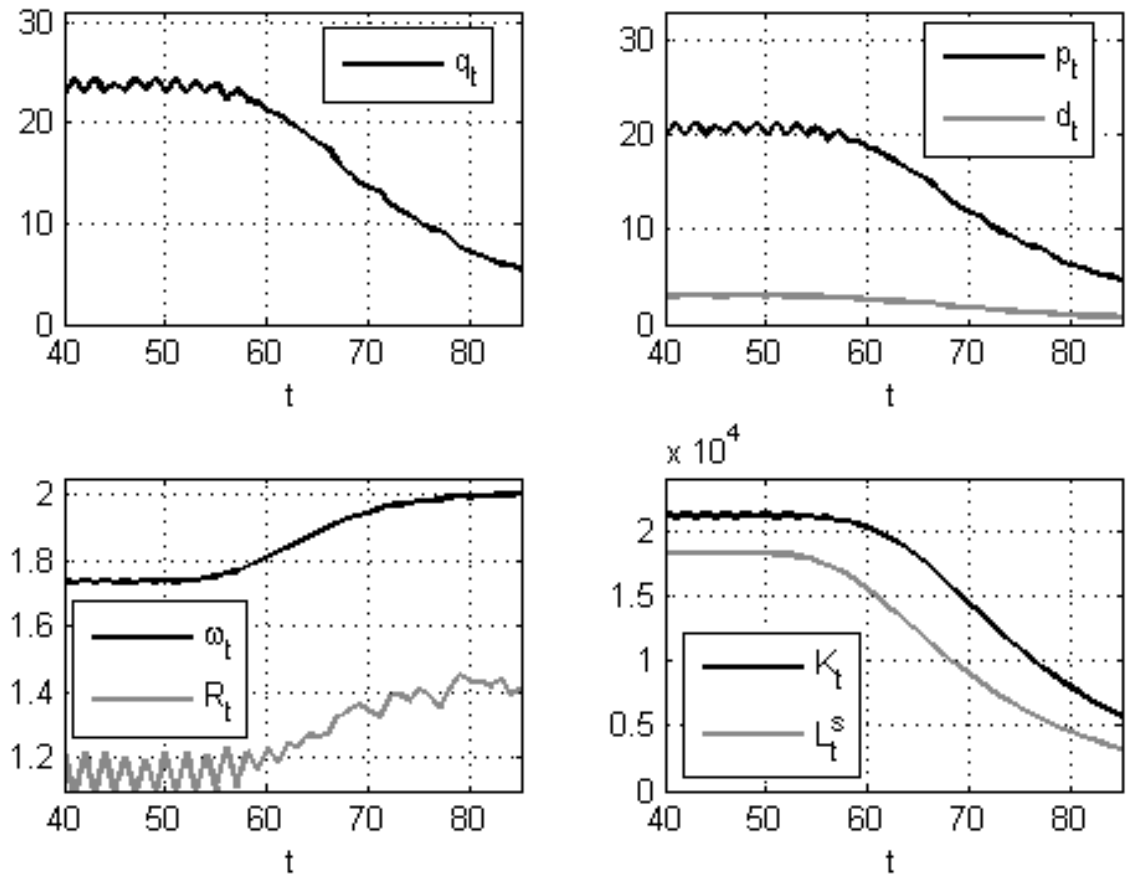

The impact on the welfare of random process in the production function. consumers is shown in figure 8 as the The curves follow the dependency ratio average of three different realizations of the with a slight delay. 
Figure 8. Welfare for constant contribution rate and demographic change

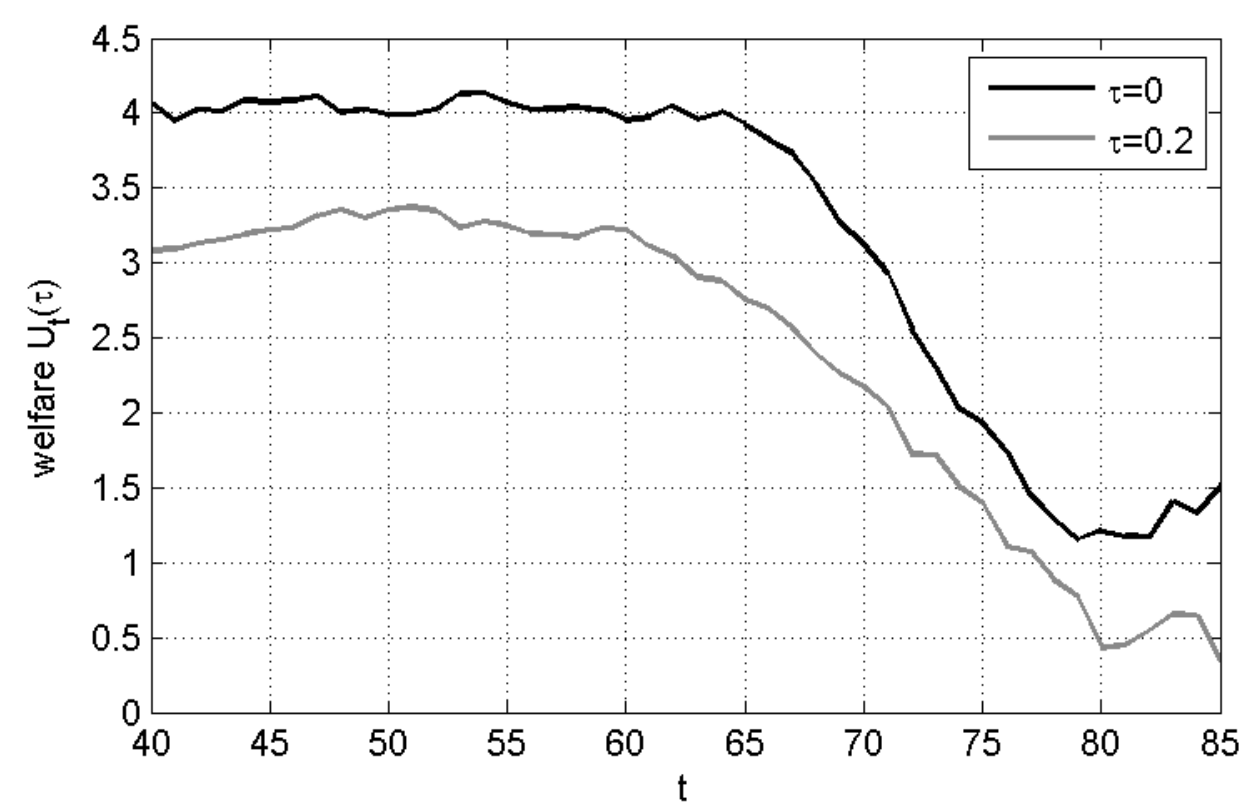

The decline is independent of the contribution rate. For $\tau=0$ the decline is reduced and the welfare is always larger compared to the case of $\tau=0.2$. It turns out that demographic change with constant contribution rates will leads to drastic losses in consumer welfare.

\section{Rates}

\subsection{Increasing the Contribution}

The decline of welfare, stock prices and capital stock as a result of demographic change raises the question whether it is possible to adapt the pension system in order to prevent or reduce these negative effects. In the following sections an existing pension system with a contribution rate of $\tau=0.2$ and a retirement threshold of $j_{L}=6$ is assumed.

One way to overcome this problem is to increase the contribution rate. Because fewer workers are facing more pensioners a higher contribution rate is needed in order to keep the pension level constant. In Germany, this is discussed in the form of the Riester/Rürup formula. In this approach, depending on the evolution of the salaries, the contribution rate in the two previous periods and the population growth, the contribution rate is increased. The dependence of consumer welfare by different variants of the formula was tested using the OLG model presented here already ${ }^{19}$. The results achieved there are consistent with those achieved in the following using a simplified linear increase of the contribution rate. As the upper limit a value of $\tau=0.31$ is assumed, because higher contributions are not politically feasible. In figure 9 the development of welfare is shown for different contribution scenarios. 
Figure 9. Welfare in case of demographic change and increasing contribution rates

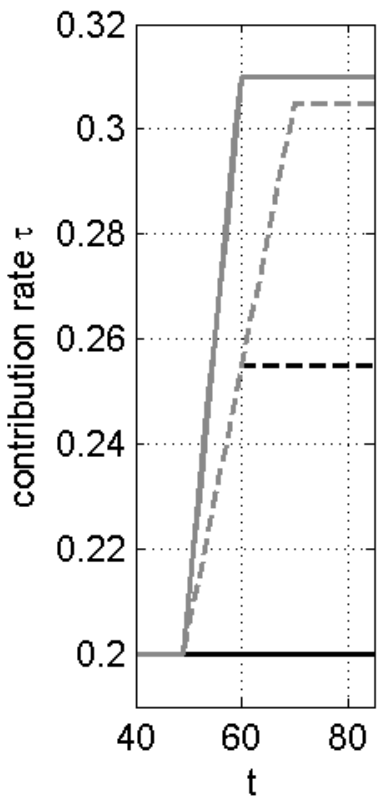

It is found that for all cases after the onset of demographic change at $t=50$ the level of welfare can be stabilized at first. The level is sometimes even higher than the reference $(\tau=0.2=$ const $)$. The initial gain is bought dearly by a sharp drop in welfare later. Starting at $t=63$ all welfare curves with increasing contribution rates fall below the reference curve and stay there. An increase in the contribution rate is therefore not an appropriate means of preventing or dampening the loss of welfare. The welfare loss is delayed at first but will be more severe later.

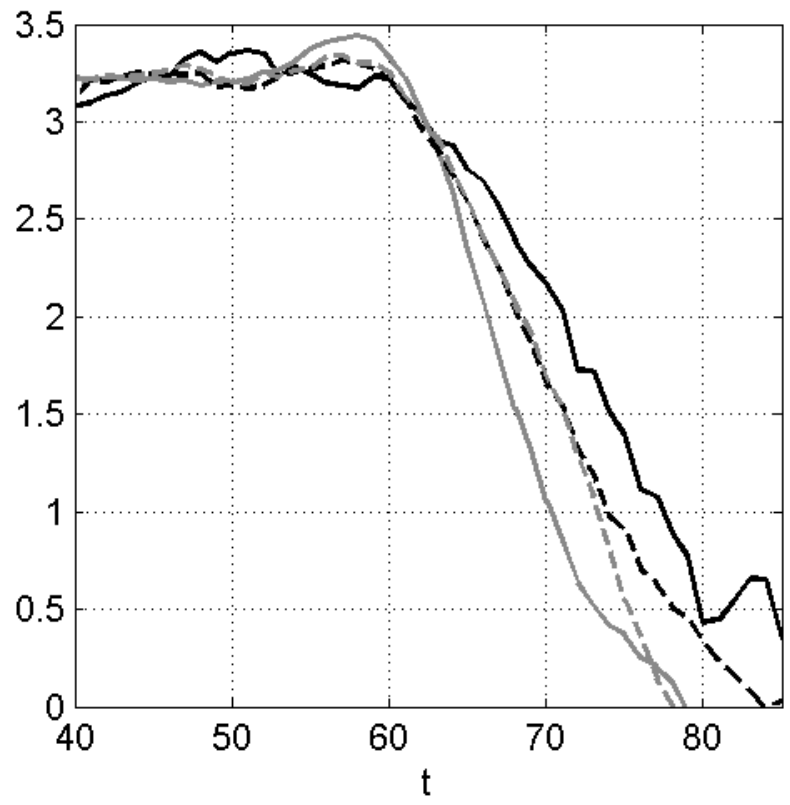

3.4. Decreasing the Contribution Rates

As an alternative to an increase in contributions, in this section a contribution reduction or gradual abolition of the payas-you-go system is examined as a way to reduce the effects of demographic change. In figure 4 it was shown that for a constant population a lower rate of contribution leads to welfare benefits. It therefore seems quite reasonable to use this potential welfare gain by lowering contribution to compensate for the loss caused by demographic effects. This is shown in figure 10 for different contribution reduction scenarios. 
Figure 10. Welfare in case of demographic change and decreasing contribution rates

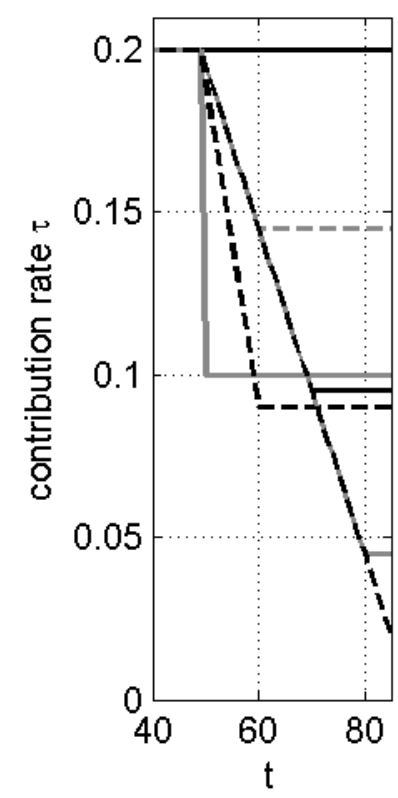

For a very abrupt reduction of the contribution rate a reduction of welfare at $t=50$ occurs, this is the result of the fact that these generations suffer from reduced pensions, but could not benefit from the low contribution rates during their working life. Afterwards for $t>60$ these cases show an increase of the welfare to values above the reference curve. This is due to the generations that benefit from the reduced contributions during their working period. This overshoot can be dampened when we pass to a slow reduction of the contributions. For all scenarios, finally the demographic effect prevails and results in a sharp decline in welfare. For all cases we find values for the welfare that lie after $t=62$ permanently above the reference curve. A reduction in contributions can therefore not prevent the loss of welfare. But it is possible to reduce the strength and to shift in time the decline of welfare.

\subsection{Raising the Retirement Age}

The analysis so far has dealt only with the contribution rate adjustments to adapt the pension system to demographic development. If we assume that the retirement age is not determined by the physical abilities of workers but is determined by policy, this limit can be considered as a variable parameter. Furthermore, this is the only reform option that directly attacks the elderly dependency ratio by increasing the number of workers and reducing the number of pensioners. In previous studies a value of $j_{L}=6$ has been consistently used. In figure 14, the evolution of welfare for different time periods for the raising of the retirement age from $j_{L}=6$ to $j_{L}=5$ is shown. In all cases the contribution rate is decreased linearly between $t=50$ and $t=89$ from $\tau=0,2$ to $\tau=0$. 
Figure 11. Welfare in case of raising the retirement threshold and reduction of contribution rates

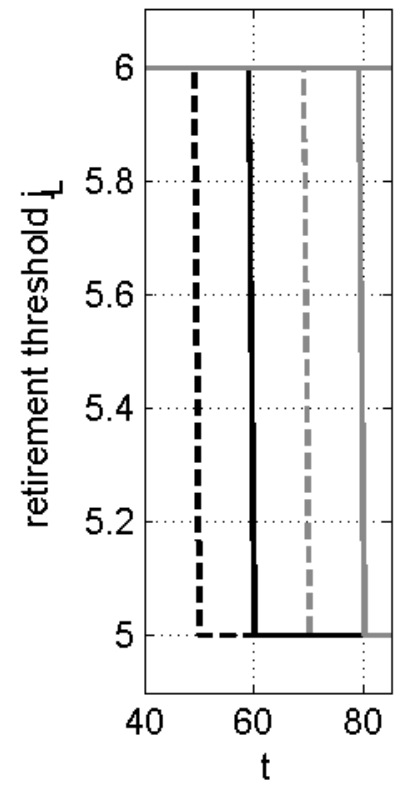

Increasing the retirement age leads in the case of an early increase to a leap in the evolution of the welfare. This is due to the generations who receive an additional period of working income instead of a pension. Also, the pension of the older generations is increased. Nevertheless, the demographic effect leads to a decline in welfare. Compared to the scenarios with constant retirement age we find the possibility to reduce the decline of welfare. It is possible to get closer to the goal of a constant welfare if the retirement threshold is increased at a time around $t=70$. Here the jump in welfare counteracts the demographic effect leading to a welfare evolution that is still decreasing but is much more stable than in previous cases. To ultimately find a welfare curve which is as flat as possible shorter time steps should be used.

\section{CONCLUSION}

The impact of an aging population is broader than its financial impact on public budgets within a pay-as-you-go pension scheme. Demographic changes will affect the entire economy by affecting productivity, savings, consumption, interest rates and asset valuations. In the context of the introduced macroeconomic model, we have shown a drastic fall of capital market returns due to an aging population. Therefore, a capital funded pension system is also influenced negatively by demographic changes. Moreover, we examined which effect the demographic changes can have on the welfare of the individuals within a payas-you-go pension system. The increasing aging of the population leads here to heavy falls in individual welfare. Different reform variants of the pension system were examined.

An increase of pension age at simultaneous lowering of the contributions and gradual abolition of the financed pension system proves to be the best possibility not to remove but to reduce the welfare loss of the consumers due to demographic changes as far as possible. On the other hand, a policy with increases in contributions as a consequence of the demographic change shows the heaviest welfare losses. Taken into account the recent pension reforms in Germany 
(increase of regular retirement age from 65 to 67 , introduction of a sustainability factor to limit the increase of contribution), a stronger increase in the retirement age or a faster transition from a pay-as-you- go pension system to a capital funded one would make sense from our point of view. But with an aging electorate, it is questionable whether such a policy will be enforceable ${ }^{20}$.

\section{REFERENCES}

1. Abel, A. B. (2001), Will Bequests Attenuate the Predicted Meltdown in Stock Prices when Baby Boomers Retire?, in: Review of Economics and Statistics, Vol. 83(4), pp. 589-595.

2. Abel, A. B. (2003), The Effects of a Baby Boom on Stock Prices and Capital Accumulation in the Presence of Social Security, in: Econometrica, Vol. 71(2), pp. 551-578.

3. Altig, D./Auerbach, A. J./Kotlikoff, L. J./Smetters, K. A./Walliser, J. (2001), Simulating Fundamental Tax Reform in the United States, in: American Economic Review, Vol. 91(3), pp. 574-595.

4. Börsch-Supan, A./Heiss, F./Ludwig, A./Winter, J. (2003), Pension Reform, Capital Markets and the Rate of Return, in: German Economic Review, Vol. 4(2), pp. 151-181.

5. Börsch-Supan, A./Ludwig, A (2011), Old Europe Ages: Reforms and Reform Backlashes, in: Shoven, J. B. (ed.), Demography and Economy, pp. 169-208.

6. Börsch-Supan, A./Ludwig, A./Winter, J. (2006), Ageing, Pension Reform and Capital Flows: A Multi-Country Simulation Model, in: Economica, Vol. 72, pp. 625-658.

7. Breyer, F. (2010), Rentenversicherung zwischen Nachhaltigkeit und Gerechtigkeit, in: Zeitschrift für die gesamte Versicherungswissenschaft, Band 99, pp. 569-583.

8. Duval, R. (2003), The Retirement Effects of Old-Age Pension systems and other Social Transfer Programmes in OECD countries, OECD Economics Department, Working Paper No. 370.

9. Gräf, B./Schattenberg, M. (2006), Die demografische Herausforderung-Simulation mit einem überlappenden Generationenmodell, Deutsche Bank Research, Februar 2006, http://www.dbresearch.de/PROD/DBR_INTERNET_DE-PROD/ PROD0000000000196139.pdf (Seitenaufruf 19. November 2010)

10. Hillebrand, M. (2008), Pension Systems, Demographic Change and the Stock Market, Berlin: Springer.

11. Hurd, M. D. (1989), Mortality Risk and Bequests, in: Econometrica, Vol. 57(4), pp. 779-813.

12. Kohler, H. P./Billari, F. C./Ortega, J. .A. (2006), Low fertility in Europe: Causes, Implications and Policy options, in Harris, F. R. (ed.), Who will do the work? Who will pay the taxes?, pp. 48-109. 
13. Krueger, D./Ludwig, A. (2007), On the Consequences of Demographic Change for Rate Returns to Capital and the Distribution of Wealth and Welfare, in: Journal of Monetary Economics, Vol. 54, pp. 49-87.

14. Preston, S. H./Hartnett, C. S. (2011), The Future of American Fertility, in: Shoven, J. B. (ed.), Demography and Economy, pp. 169-208.

15. Shoven, J. B./Goda, G. S. (2011), Adjusting Government policies for Age Inflation, in: Shoven, J. B. (ed.), Demography and Economy, pp. 169-208. 